\title{
EVALUASI PENANGANAN KEMASAN UBC DI BANK SAMPAH DAN PENGEPULNYA MENGGUNAKAN PENDEKATAN ERGONOMI PARTISIPASI
}

\author{
Helena Juliana Kristina ${ }^{1}$, Wilson Kosasih ${ }^{2}$, Lithrone Laricha Salomon ${ }^{3}$ \\ Program Studi Teknik Industri, Fakultas Teknik Universitas Tarumanagara \\ e-mail: julianak@ft.untar.ac.id ${ }^{1}$,wilsonk@ft.untar.ac.id ${ }^{2}$, lithrones@ft.untar.ac.id ${ }^{3}$
}

\begin{abstract}
ABSTRAK
Dalam jangka panjang, industri di Indonesia dihimbau untuk menerapkan prinsip ekonomi sirkular. Nilai dari sebuah produk atau material dijaga dan dimanfaatkan selama mungkin, sehingga timbunan sampah dapat dibatasi sekecil mungkin. PT. Tetra Pak telah melakukan pendekatan open loop model ekonomi sirkular. Sejak 2018 hingga sekarang, proyek pengumpulan kemasan UBC telah dilakukan menggunakan pendekatan ergonomi partisipasi, sebagai tabungan sampah terpilah di Tangerang Selatan. Tujuan penelitian ini adalah mengevaluasi penanganan kemasan UBC di tingkat bank sampah dan pengepulnya di Kota Tangsel, sebagai bagian dari bentuk dialog yang konsisten. Metode pengambilan data dilaksanakan dengan wawancara, diskusi dan penyebaran kuesioner. Hasil evaluasi menunjukkan bahwa perlu terus dibangun hubungan kerja sama, saling menghargai dan memahami antara semua mitra dalam kegiatan yang sudah berjalan. Hasil evaluasi juga menunjukkan opini dari pengurus bank sampah bahwa PT. Tetra Pak Indonesia sudah peduli pada permasalahan sampah kemasannya.
\end{abstract}

Kata kunci: Ergonomi Partisipasi, Pengelolaan Sampah, Daur Ulang, UBC, Tetra Pak, Ekonomi Sirkular.

\begin{abstract}
In the long term, industries in Indonesia are encouraged to apply the principle of a circular economy. The value of a product or material is maintained and utilized for as long as possible, so that landfill can be limited as little as possible. PT. Tetra Pak has approached the open loop model of circular economy. Since 2018 until now, UBC's packaging collection project has been carried out using a participatory ergonomics approach, as savings for segregated waste in South Tangerang. The aim of this study is to evaluate the handling of UBC packaging at the waste bank and collectors level in Tangsel City, as part of a consistent form of dialogue. The data collection method was carried out by interview, discussion and questionnaire distribution. The results of the evaluation shown that it is necessary to continue to build cooperative relationships, mutual respect and understanding between all partners in ongoing activities. The evaluation results also shown the opinion of the waste bank management that PT. Tetra Pak Indonesia already cares about the problem of packaging waste.
\end{abstract}

Keywords: Ergonomics Participation, Waste Management, Recycle, UBC, Tetra Pak, Circular Economy.

\section{PENDAHULUAN}

Di dalam PERPRES NO 97 Tahun 2017 yang berisi tentang kebijakan dan strategi pengolahan sampah, mentargetkan sampai Tahun 2025, terjadi penanganan sampah $70 \%$ dan pengurangannya sampai $30 \%$. Hal ini dapat dilakukan dalam konteks pengelolaan sampah yang menggunakan prinsip 3R: Reduce, Reuse dan Recycle, yang menjadi pokok utama dalam UU No 18 Tahun 2008 tentang Bank Sampah, yang diperkuat dalam Peraturan Pemerintah No 81 Tahun 2012 tentang Pedoman Pelaksanaan Program Pengelolaan Sampah Kota dan Sampah Sisa Rumah Tangga. Bank sampah merupakan program pemerintah yang berbasiskan partisipasi masyarakat, yang keberadaannya diharapkan mengubah paradigma masyarakat mengenai pengelolaan sampah pada sumbernya dengan penerapan prinsip 3R [1]. Program bank sampah yang sudah ada di Indonesia dapat digunakan sebagai salah satu pintu masuk terwujudnya reverse logistic rantai pasok manufaktur berkelanjutan [2], karena program bank sampah adalah praktisnya dari penerapan konsep hubungan ekonomi dan ekologi. Industri dihimbau, dalam jangka 
panjang menggunakan prinsip circular economy, dimana nilai produk atau materialnya dipertahankan dan dimanfaatkan selama mungkin, sehingga timbunan sampah dapat dibatasi sekecil mungkin. Circular economy adalah suatu sistem regenerative di mana input sumber daya dan pemborosan, emisi dan kebocoran energi diminimalkan dengan memperlambat, menutup, dan mempersempit putaran energi dan material, dimana hal ini dapat dicapai melalui pemeliharaan, perbaikan, penggunaan kembali, remanufaktur, perbaikan, dan daur ulang [3].

PT. Tetra Pak telah melakukan pendekatan Open Loop Model dari konsep ekonomi sirkular. Mereka meyakini bahwa post consumed recycling merupakan investasi untuk masa depan, dimana konsumen menjadi semakin sadar akan keberlanjutan lingkungan yang ada dalam setiap kemasan makanan/minuman. Kemasan karton bekas minuman (UBC) merupakan bahan baku yang bernilai bagi industri lain, seperti industri kertas daur ulang, furniture, roofing. PT Tetra Pak telah melakukan kerjasama mengembangkan infrastruktur pengumpulan ini sejak tahun 2005 yang diinisiasi bersama BBPK (Balai Besar Pulp dan Kertas), dengan mitra pengumpul seperti EcoBali, Yapsi, Armada Kemasan Nusantara, Waste4Change, Bina Usaha Mandiri, dimana saat ini telah mencapai lebih dari 100 collection points di pulau Jawa - Bali. Mitra pabrik untuk proses daur ulang berlokasi di Tangerang dan Mojokerto [4].

Tahun 2018 dilakukan pengumpulan kemasan UBC sebagai tabungan sampah terpilah di 16 bank sampah di Tangerang Selatan. Sebelumnya, kemasan UBC belum masuk sebagai jenis sampah yang bernilai ekonomis di bank sampah, dan perlakuan yang diberikan pengepul hanya dibakar, sekarang sudah terbentuk jaringan rantai pasok daur ulangnya di Tangsel, dengan nama jenis tabungan sampah "tetra pak". Dari hasil pengukuran berat penimbangan UBC di bank sampah percontohan sebelum insentif dan sesudah insentif diberikan tidak berbeda signifikan. Hal ini membuktikan bahwa berat penimbangan kemasan tetra pak di bank sampah percontohan saat itu sudah cukup stabil/konsisten [5]. Di tahun 2019 (Maret sampai Juli 2019) juga telah dilaksanakan proyek percontohan pengumpulan dan pemilahan sampah kemasan tetra pak dan sampah anorganik lainnya di RT 03 Serpong Terrace BSD-Tangsel. Hasil kelanjutan kegitan ini akan diteruskan oleh pengurus RT bersama mitra pengepul SampaQu. Secara keseluruhan, projek ini cukup berhasil, dikarenakan tujuan tercapai, ada partisipasi dari semua mitra, bahkan beberapa mitra memberikan partisipasinya melebihi target rencana awal [6].

Dikarenakan bank sampah menggunakan prinsip pemberdayaan masyarakat, maka dibutuhkan dialog yang konsisten dengan pengurus komunitasnya. Hal ini dilakukan guna memelihara tali silahturahmi dan dukungan kemitraan untuk berpartisipasi membangun jejaring dan mekanisme kerjasama antara bank sampah, pengepul sampah, relawan sosial, lingkungan dan pihak industri. Dalam pendekatan ergonomi, partisipasi merupakan terlibatnya orang secara mental dan emosional di dalam satu komunitas yang merangsang mereka untuk berkontribusi kepada tujuan kelompok dan berbagi tanggung jawab untuk apa yang dihasilkannya [7]. Pendekatan ergonomi partisipasi, mengharapkan seluruh peserta memiliki keterlibatan langsung dalam perencanaan dan pelaksanaan tugas-tugas mereka, seperti adanya rapat yang bertujuan untuk saling bertukar pikiran maupun menyumbangkan ide-ide yang dapat digunakan untuk menyelesaikan tugas dengan baik dan sempurna [8].

Hal ini, dikarenakan dalam pemberdayaan berkelanjutan, diperlukan prinsip kegiatan ekonomi harus membuka dirinya pada berbagai sumber sosial budaya dan lingkungan yang memiliki dimensi jangka panjang, yang ada kemungkinan memiliki interaksi yang rumit [9]. Dalam merancang kualitas pemberdayaan masyarakat haruslah mempertimbangkan kemampuan dan kapasitas kinerja manusia. Semua proses sangat bergantung pada sinergi partisipan untuk bekerja secara efektif dan sukarela guna berpartisipasi dalam aktualisasi dirinya, untuk memenuhi kebutuhan mereka dalam melakukan tugas. Studi psikologi sosial 
telah memperlihatkan bahwa, berdasarkan pilihan yang ada, masyarakat lebih menyukai resiprositas sosial (pembagian bersama atau saling menguntungkan) dan kepercayaan (trust) sosial [10]. Tujuan penelitian ini adalah mengevaluasi penanganan kemasan UBC di tingkat bank sampah dan pengepulnya di Kota Tangsel, sebagai bagian dari bentuk menciptakan dialog yang konsisten.

\section{METODE PENELITIAN}

Penelitian ini adalah eksploratory study. Unit yang dianalisis adalah pengepul sampah SAMPAHQU dan 16 pengurus bank sampah. Metode pengumpulan data evaluasi dilakukan dengan pengisian kuesioner terstruktur dan diskusi. Kuesioner evaluasi penanganan sampah terpilah kemasan tetra pak di bank sampah, berisi indikator pengetahuan pengurus bank sampah akan asal dan kondisi tabungan sampah UBC nasabah, penanganan sampah UBC dan keterlibatan pengurus dalam praktek pribadi maupun edukasi daur ulang ke nasabahnya.

Pengumpulan data kuantitatif dan kualitatif penimbangan UBC di bank sampah selama tahun 2019 juga dilakukan, dengan wawancara kepada pengepul. Penelitian ini juga melihat variabel pengelolaan partisipatoris model ABA (Applied Behavioral Analysis) [8], merupakan sebuah pendekatan untuk mempromosikan perilaku melestarikan, yang dapat menjadi kunci sukses manajemen partisipasi milik bersama sebagai modal sosial untuk mendukung keberhasilan kegiatan komunitas. Secara garis besar model ABA untuk penelitian ini adalah sebagai berikut:

Perilaku partisipasi + Imbalan (fisik \& non fisik) $=$ Partisipasi Terus Dilakukan

Perilaku partisipasi - Imbalan (fisik \& non fisik) = Partisipasi Akan Terhenti

Yang dimaksud dengan imbalan disini, tentu saja bukan hanya dalam bentuk uang semata, melainkan dapat berupa benda/produk "hijau" seperti pemberian souvenir, bantuan komposter, pupuk dan lain-lain. Sedangkan, bentuk non fisik seperti ilmu pengetahuan, apresiasi, penerimaan dalam komunitas dan lainnya. Kegiatan evaluasi dikemas dalam acara sarasehan, dengan pemberian imbalan berupa ilmu pengetahuan pengolahan sampah organik dan pemberian souvenir untuk praktik pengolahan sampah organik dengan BC (Bio-compound) dan uang pengganti transport partisipan sebesar Rp 100.000,-.

\section{HASIL DAN PEMBAHASAN}

Pengumpulan UBC yang dilakukan oleh pengepul sampah SampahQu, menggunakan 2 cara, yaitu dengan bantuan mitra bank sampah dan dengan pengumpulan mandiri (pengepul mencari sendiri sumber keberadaan sampah UBC di Tangsel). Hasil pengumpulan thn 2019 dapat dilihat pada Tabel 1. Tahun 2019, pengepul SampahQu sudah berhasil mengumpulkan $728,13 \mathrm{~kg}$ UBC di Tangsel untuk dibawa ke pabrik daur ulang, dengan perincian dari bank sampah 437,13 kg dan yang dikumpulkan secara mandiri oleh SampahQu sebesar $291 \mathrm{~kg}$.

Hasil Tabel 1 - sesuai dengan penelitian sebelumnya - menunjukkan bahwa ketika pengepul hanya berharap penimbangan kemasan tetra pak di bank sampah pada kisaran rata-rata $0,2 \mathrm{~kg}$ per penimbangan, maka tingkat kegagalannya hanya $1 \%$. Tetapi jika pengepul menargetkan penimbangan tetra pak $10 \mathrm{~kg} /$ penimbangan pada bank sampah, maka estimasi tingkat kegagalannya akan menjadi 95\% [4].

Tabel 1. Rekapitulasi Penimbangan Kemasan UBC di 17 Bank Sampah dan Pengepulnya

\begin{tabular}{lccccccccc}
\hline \multicolumn{1}{c}{ Statistik UBC SampahQu } & $\begin{array}{c}\text { Januari } \\
\text { 2019 }\end{array}$ & $\begin{array}{ccccc}\text { 2019 } \\
\end{array}$ & $\begin{array}{c}\text { Maret } \\
\mathbf{2 0 1 9}\end{array}$ & $\begin{array}{c}\text { April } \\
\mathbf{2 0 1 9}\end{array}$ & $\begin{array}{c}\text { Mei } \\
\mathbf{2 0 1 9}\end{array}$ & $\begin{array}{c}\text { Juni } \\
\mathbf{2 0 1 9}\end{array}$ & $\begin{array}{c}\text { Juli } \\
\mathbf{2 0 1 9}\end{array}$ & $\begin{array}{c}\text { Agustus } \\
\mathbf{2 0 1 9}\end{array}$ & $\begin{array}{c}\text { Sep } \\
\mathbf{2 0 1 9}\end{array}$ \\
\hline Non Bank Sampah $(\mathrm{kg})$ & 95.00 & 22.00 & 34.00 & 26.00 & 25.00 & 13.00 & 20.00 & 29.00 & 27.00 \\
Bank sampah $(\mathrm{kg}) \mathrm{n}=17$ & 60.43 & 41.8 & 33 & 34.6 & 14.8 & 97.42 & 54.04 & 70.91 & 30.13 \\
Total keseluruhan $(\mathrm{kg})$ & 155.43 & 63.80 & 67.00 & 60.60 & 39.80 & 110.42 & 74.04 & 99.91 & 57.13 \\
rata-rata keseluruhan $(\mathrm{kg})$ & 8.64 & 3.54 & 3.72 & 3.37 & 2.21 & 6.13 & 4.11 & 5.55 & 3.17 \\
rata-rata bank sampah $(\mathrm{kg}) \mathrm{n}=17$ & 3.55 & 2.46 & 1.94 & 2.04 & 0.87 & 5.73 & 3.18 & 4.17 & 1.77 \\
\hline
\end{tabular}


Helena Juliana Kristina, Wilson Kosasih, Lithrone Laricha S.

Gambar 1 memperlihatkan UBC di lahan pengepul SampahQu. Hasil wawancara dengan pengepul SampahQu, bahwa pihak pabrik tetap memotong 25\% UBC yang dikirimnya, walaupun sudah dikemas dengan baik dan kondisi UBC jauh lebih bersih daripada pengepul dari TPA. Hal ini sama dengan tahun sebelumnya, dimana pengepul mengirim dalam keadaan pres manual dan packaging karung serta mengandung sedotan, maka dari checker mendapat potongan $25 \%$ dari harga belinya, dan hal ini merugikan pengepul [4].

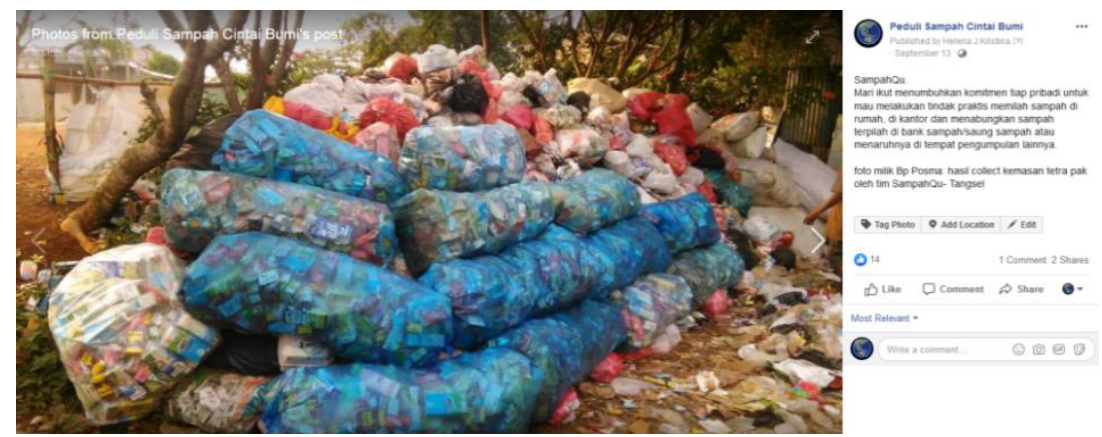

Gambar 1. Foto Pengumpulan UBC di Lahan Pengepul SampahQu dan Publikasinya.

Gambar 2 menunjukkan hasil evaluasi pengolahan data kuesioner penanganan kemasan tetra pak di bank sampah percontohan. Dari hasil pengolahan data kuesioner evaluasi yang diisi 23 pengurus bank sampah, diperoleh infomasi bahwa 91\%, para pengurus bank sampah sudah menginfokan kepada nasabahnya bahwa kemasan Tetra Pak adalah jenis tabungan sampah tersendiri, bukan dicampur dengan jenis boncos ataupun jenis campur sari.

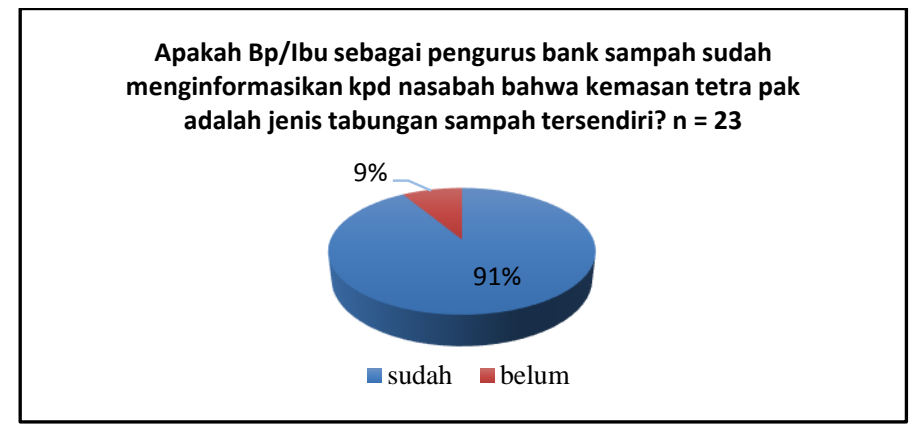

Gambar 2. Distribusi Penyampaian Informasi kepada Nasabah bahwa Kemasan Tetra Pak adalah Jenis Tabungan Sampah Tersendiri

Gambar 3 memperlihatkan infomasi banyak/sedikit sampah kemasan Tetra Pak di wilayah bank sampah percontohan. Terlihat dari gambar, $48 \%$ menjawab banyak dan $43 \%$ menjawab sedang.

Menurut Bp/lbu, banyak kah jenis sampah tetra pak di wilayah tempat tinggal $\mathrm{Bp} / \mathrm{lbu}$ ? $\mathrm{n}=\mathbf{2 3}$

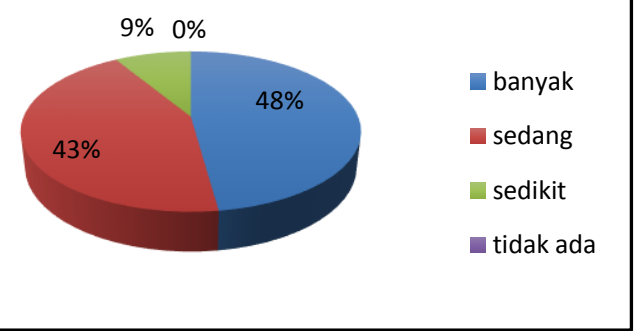

Gambar 3. Distribusi Banyak atau Sedikitnya Jenis Sampah Kemasan Tetra Pak di Wilayah Tempat Tinggal dimana Bank Sampah Beroperasi 
Gambar 4 memperlihatkan perolehan sampah kemasan Tetra Pak paling banyak 57\% adalah dari rumah sendiri, tetangga dan teman.

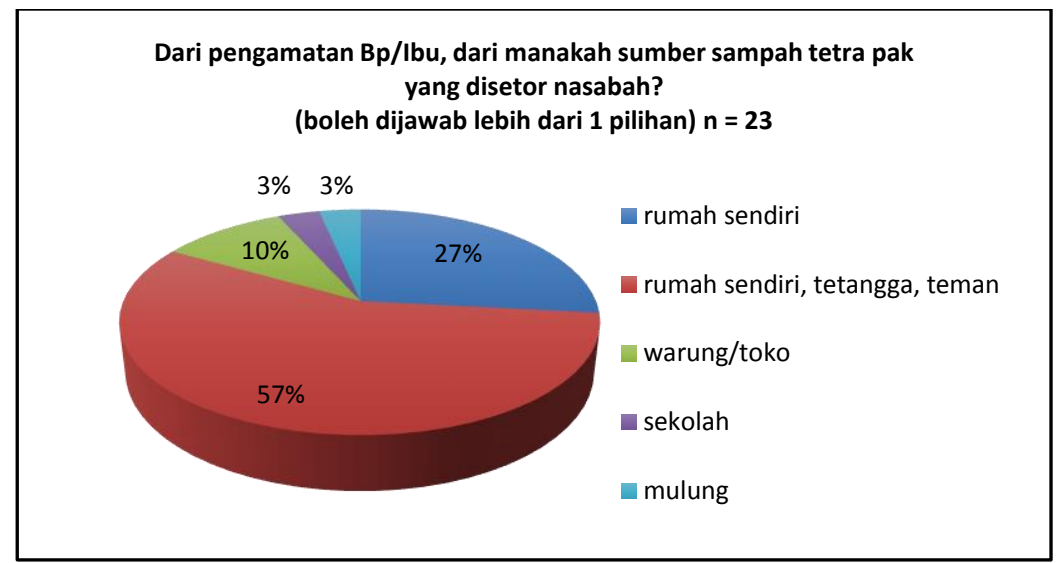

Gambar 4. Distribusi Sumber Perolehan Jenis Sampah Kemasan Tetra Pak dimana Bank Sampah Beroperasi

Gambar 5 memperlihatkan informasi bahwa meskipun pengurus bank sampah sudah menginfokan kepada nasabahnya bahwa kemasan Tetra Pak adalah jenis tabungan sampah terpilah, masih ada 5\% yang menyatakan bahwa nasabah bank sampah mereka yang menggabungkan jenis Tetra pak dengan jenis tabungan sampah lainnya. Alasannya adalah nasabah masih belum mengerti kategori pemilahan ataupun jenis Tetra Pak saat penimbangan terlalu sedikit, sehingga nasabah menggabungnya dengan jenis lain. Alasan lainnya adalah belum sempat melakukan pemilahan jadi hanya mengumpulkan saja. Demikian juga untuk nasabah baru, pengurus kurang memberi informasi kepada nasabah, dan butuh waktu agar nasabah paham jenis jenis sampah terpilah.

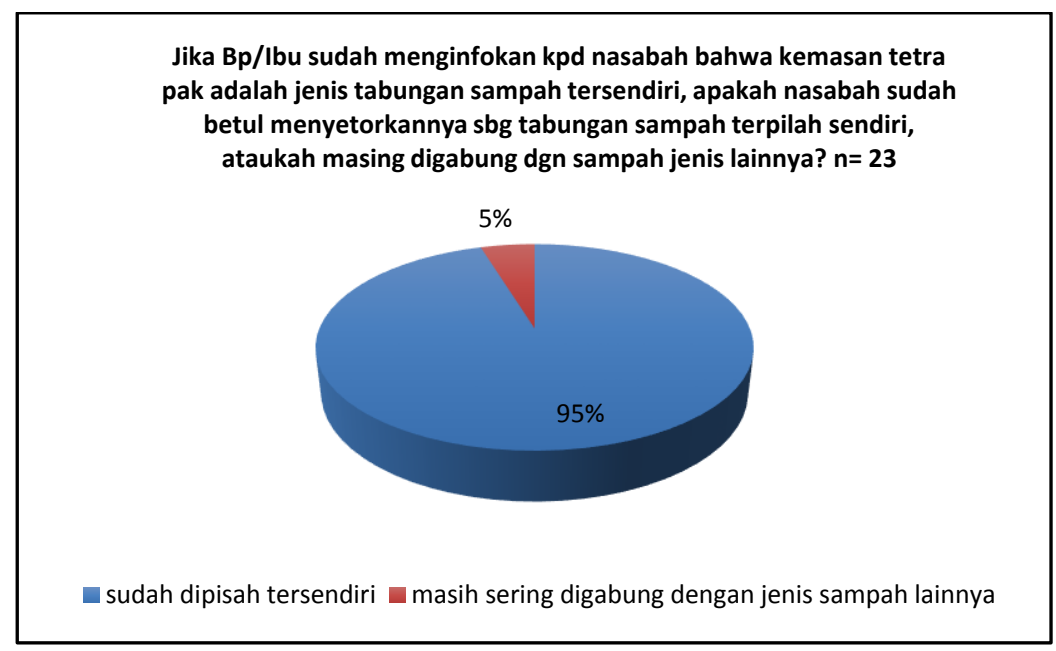

Gambar 5. Distribusi Sumber Perolehan Jenis Sampah Kemasan Tetra Pak dimana Bank Sampah Beroperasi

Gambar 6 menunjukkan bahwa kondisi kemasan Tetra Pak yang disetorkan ke bank sampah pada umumnya bahan dalam kondisi baik, dimana 50\% bersih dan sudah dilipat dengan rapi, $19 \%$ bersih dan tidak dilipat, 19\% kotor karena cairan dalam dusnya dan kondisi sudah dilipat, 6\% kotor karena cairan dalam dusnya dan kondisi tidak dilipat. Apabila kotor disebabkan karena cairan minuman dari dalam UBC saja, bukan karena kontaminasi material dari luar. 


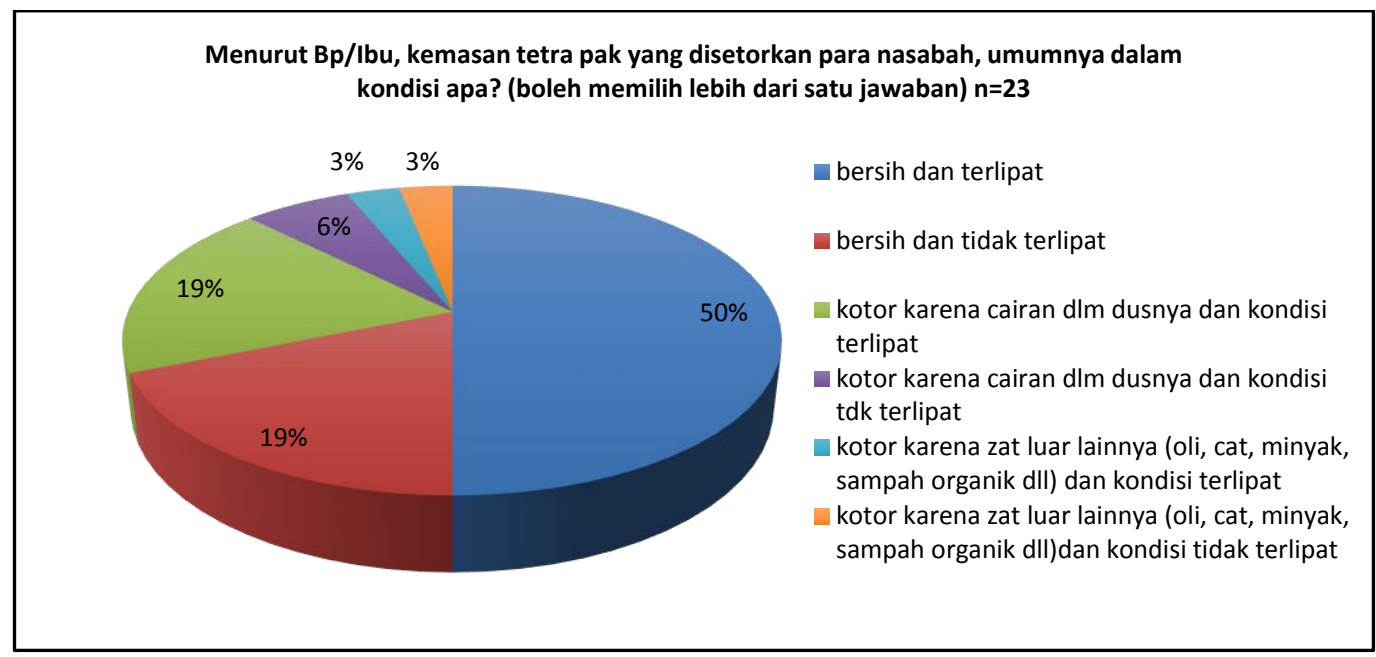

Gambar 6. Distribusi Kondisi Jenis Kemasan Tetra Pak yang Disetor ke Bank Sampah secara Umum

Peranan pengurus dalam menyampaikan edukasi 3L untuk perlakukan kemasan Tetra Pak sangatlah penting. Gambar 7, penanganan 3 L untuk UBC ukuran besar, memperlihatkan bahwa $83 \%$ partisipan melakukan langkah "buka-tutup", buka lipatan, pisahkan tutup plastiknya dan kardusnya di tempat sampah terpilah. Partisipan yang melakukan hal ini, dikarenakan tutup plastik UBC dimasukkan ke jenis tabungan sampah bucket, yang mempunyai harga lebih tinggi daripada Tetra Pak. Juga terlihat 17\% partisipan yang melakukan langkah "buka-tutup", dikempiskan, pasang kembali tutupnya, masukkan tempat sampah terpilah.

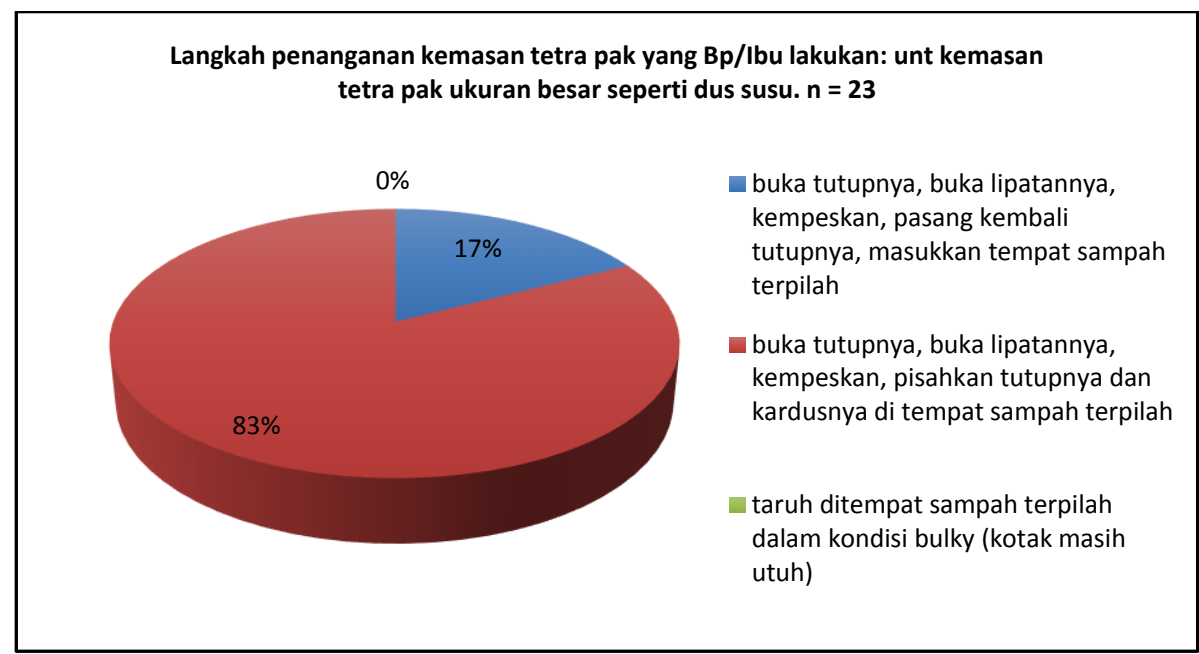

Gambar 7. Distribusi Konfirmasi Pengetahuan Pengurus Bank Sampah akan 3L UBC Ukuran Besar

Untuk UBC ukuran kecil (lihat Gambar 8), dapat dilihat bahwa 65\% partisipan melakukan langkah: memasukkan sedotan, buka lipatannya, kempiskan, masukkan ke tempat sampah terpilah. Kemudian 33\% melakukan langkah: membuang sedotan, buka lipatannya, masukkan ke tempat sampah terpilah. 3L UBC ukuran kecil pada masa mendatang masih harus diedukasi dikarenakan sampah sedotan akan berbahaya bagi lingkungan hidup jika tercecer, sehingga sedotan dalam sampah UBC ukuran kecil seharusnya dimasukkan ke dalam kotak UBC. Hal tersebut disebabkan di pabrik sedotan dan UBC akan langsung masuk ke dalam mesin daur ulang tanpa perlu dipisahkan. 


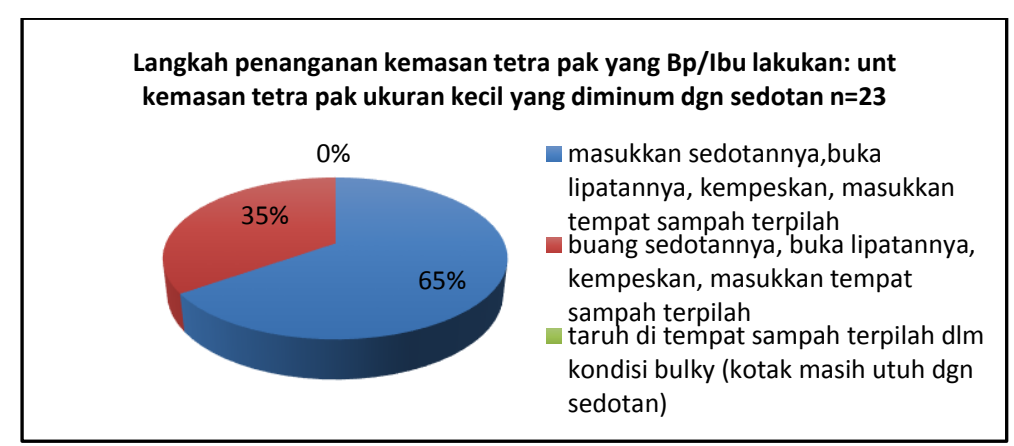

Gambar 8. Distribusi Konfirmasi Pengetahuan Pengurus Bank Sampah akan 3L UBC Ukuran Kecil

Gambar 9 menunjukkan bahwa 83\% pengurus bank sampah percontohan mengkonfirmasi bahwa semua nasabahnya sudah mengetahui bahwa kemasan Tetra Pak bisa di daur ulang. Pengurus bank sampah yang menjawab tidak yakin bahwa semua nasabahnya mengetahui, dikarenakan adanya nasabah-nasabah baru, dan pengurus kurang memberi informasi kepada nasabah.

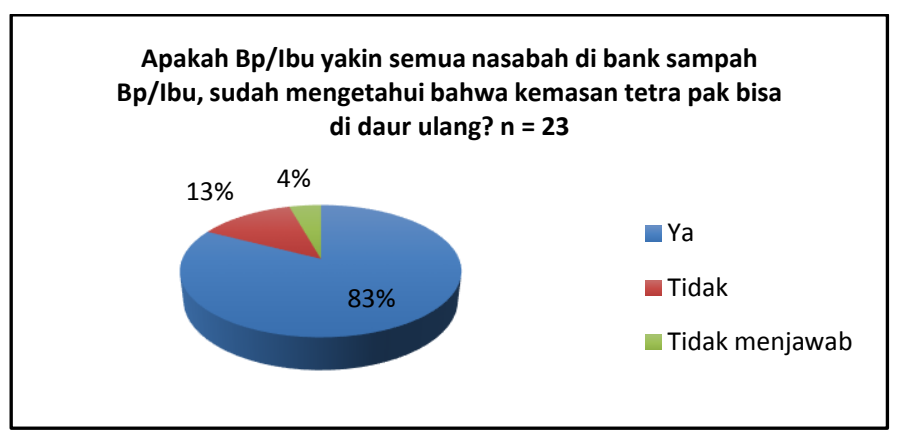

Gambar 9. Distribusi Konfirmasi Apakah Semua Nasabah di Bank Sampah Percontohan sudah Mengetahui bahwa Kemasan Tetra Pak Dapat Di-daur Ulang

Konfirmasi kecenderungan alasan utama mengapa nasabah mau memilah dan menabung sampah, diketahui bahwa 74\% menjawab karena peduli lingkungan hidup, 26\% menjawab karena nilai ekonominya (lihat Gambar 10).

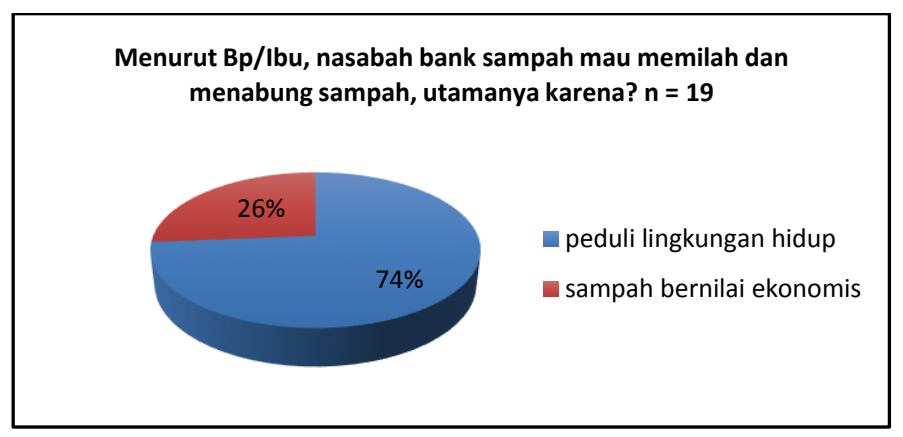

Gambar 10. Distribusi Konfirmasi Kecenderungan Alasan Utama Nasabah Berkeinginan untuk Memilah dan Menabung Sampah

Para partisipan juga mengatakan ada pengalaman baik ketika pengurus bank sampah menangani Tetra Pak sebagai tabungan sampah terpilah. Pada umumnya mengatakan nasabah memberikan respon positif, mereka menjadi bersemangat mengumpulkan Tetra Pak karena tahu kemasan itu ada nilai rupiahnya, dan dapat menambah tabungan sampah. Selain itu, baik untuk mengajarkan praktik kepada anak-anak mereka, agar sehabis minum 
Helena Juliana Kristina, Wilson Kosasih, Lithrone Laricha S.

Susu kemasan langsung memisahkan kemasan Tetra Pak untuk disetor ke bank sampah. Ada juga yang menyatakan bahwa jenis ini tidak terjual di lapak pemulung. Akan tetapi jenis ini cukup banyak dibuang orang di jalan, maka nasabah mereka yang memulung dan disetor ke bank sampah. Ada juga pengurus yang merasa bangga, karena kemasan Tetra Pak hanya diterima di bank sampah mereka, sedangkan bank sampah lain belum ada. Pengurus lain mengatakan pengalaman baiknya adalah senang melihat kemasan Tetra Pak yang terkumpul dan terlipat rapi, yang menandakan nasabahnya peduli dan rajin.

Selain pengalaman baik, juga ada pengalaman buruk yang dirasakan pengurus bank sampah percontohan selama menangani kemasan Tetra Pak sebagai jenis tabungan sampah terpilah. Mereka mengeluh sering menghirup aroma susu yang basi saat penimbangan dilakukan, ada pengurus yang berinisiatif mengosongkan isi kemasan, tetapi sudah terlalu berbau dan susah dikeluarkan sisa isi cairannya. Pengurus juga mengeluhkan, kadang mendapat isi kemasan yang tidak habis diminum, sehingga waktu penimbangan cairan merembes, sehingga menjadi lengket dan bau.

Hubungan kerjasama, saling menghargai dan memahami antara semua mitra dalam kegiatan ini adalah sangat penting. Oleh karena itu, opini dari pengurus bank sampah percontohan mengenai apakah PT. Tetra Pak Indonesia sudah peduli pada permasalahan sampah kemasannya, 87\% menjawab bahwa PT. Tetra Pak Indonesia sudah peduli (lihat Gambar 11).

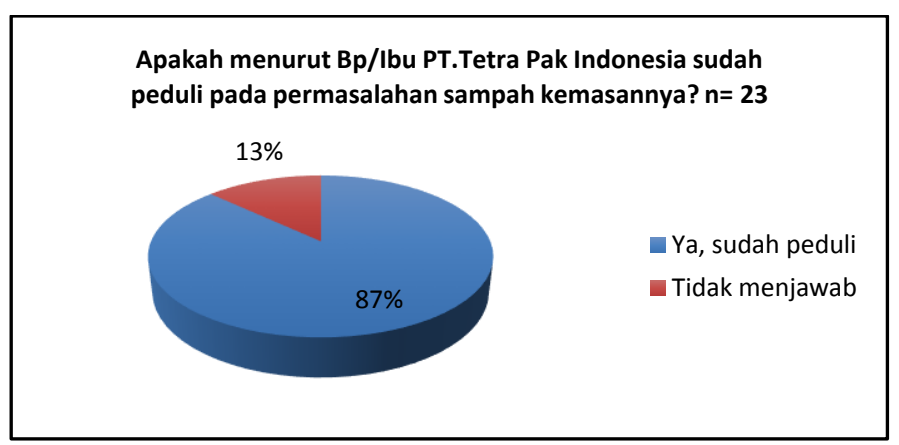

Gambar 11. Distribusi Opini Apakah PT.Tetra Pak sudah Peduli pada Permasalahan Sampah Kemasannya

Pengurus bank sampah adalah tokoh penting dalam menggerakkan roda bank sampah. Oleh sebab itu diperlukan dalam evaluasi ini, konfirmasi ulang dari para pengurus bank sampah percontohan apakah bersedia mengingatkan kembali kepada nasabahnya bahwa kemasan tetra pak bisa ditabung sebagai jenis tabungan sampah terpilah. Hal ini dikarenakan sifat manusia yang pelupa, kadang malas, jadi reminder atau pengingatan adalah penting untuk dilakukan. Gambar 12 menunjukkan $96 \%$ pengurus bersedia membantu mengingatkan nasabahnya.

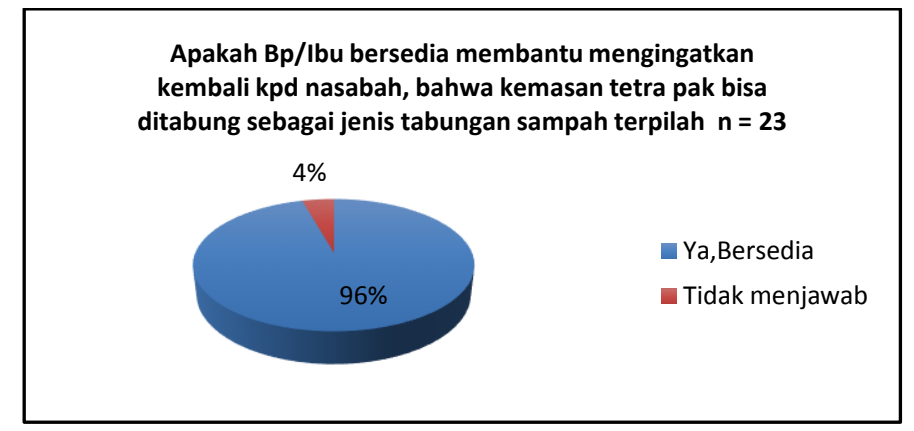

Gambar 12. Distribusi Konfirmasi Pertama Kesediaan Pengurus Bank Sampah 
Pengurus bank sampah juga bergabung dalam Silahturahmi Bank Sampah Tangsel, Mereka sering bertemu dalam acara-acara khusus bertema lingkungan hidup atau kegiatan bank sampah. Oleh karena itu adalah penting untuk mengetahui tingkat kesediaan para pengurus bank sampah ini, untuk membantu menginfokan kepada pengurus bank sampah lainnya di Tangsel bahwa kemasan Tetra Pak bisa di tabung sebagai jenis tabungan sampah terpilah. Gambar 13 menunjukkan 91\% menyatakan bersedia.

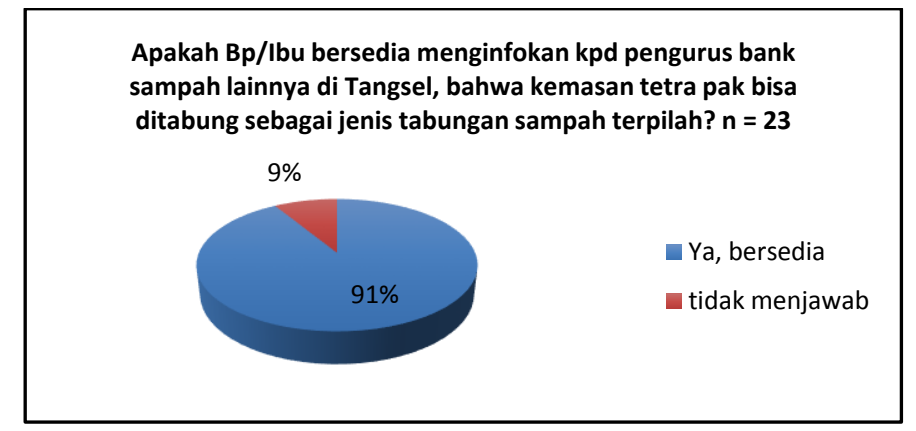

Gambar 13. Distribusi Konfirmasi Kedua Kesediaan Pengurus Bank Sampah

\section{KESIMPULAN}

Secara keseluruhan, kegiatan evaluasi berjalan dengan baik. Partisipan yang hadir ada 30 partisipan dari 14 bank sampah percontohan dan 2 pengepul sampah. Pengelolaan partisipatoris selama evaluasi diarahkan kepada usaha mewujudkan kepercayaan sosial, dan hal ini akan membantu mewujudkan suatu kegiatan mewujudkan sirkular ekonomi. Ada komitmen terhadap rasa kepemilikan kegiatan bersama, dimana setiap partisipan lebih menyukai hubungan yang mempertimbangkan kebutuhan dan manfaat, yaitu hubungan antara partisipan didasarkan pada kebutuhan untuk saling membantu dan melengkapi.

Para partisipan juga mengatakan ada pengalaman baik ketika pengurus bank sampah menangani Tetra Pak sebagai tabungan sampah terpilah. Pada umumnya mengatakan, nasabah memberikan respon positip, mereka menjadi bersemangat mengumpulkan Tetra Pak, karena tahu kemasan itu ada nilai rupiahnya, dan dapat menambah tabungan sampah. Selain itu baik untuk mengajarkan dan praktik pada anak anak mereka, agar sehabis minum susu, langsung memisahkan kemasan Tetra Pak untuk disetor ke bank sampah. Ada juga yang menyatakan, karena jenis ini tidak laku di lapak pemulung, sedangkan jenis ini cukup banyak dibuang orang di jalan, maka nasabah mereka yang memulung dan disetor ke bank sampah. Ada juga pengurus yang merasa bangga, karena kemasan Tetra Pak hanya diterima di bank sampah mereka, sedangkan bank sampah lain belum ada. Pengurus lain menggatakan pengalaman baiknya adalah senang melihat kemasan Tetra Pak yang terkumpul dan terlipat rapi, yang menandakan nasabahnya peduli dan rajin.

Selain pengalaman baik, juga ada pengalaman buruk yang dirasakan pengurus bank sampah percontohan selama menangani kemasan Tetra Pak sebagai jenis tabungan sampah terpilah. Mereka mengeluhkan sering mencium aroma susu basi saat penimbangan dilakukan, ada pengurus yang berinisiatif mengosongkan isi kemasan, tetapi sudah terlalu bau basi dan susah dikeluarkan sisa isi cairannya. Pengurus juga mengeluhkan, kadang mendapat isi kemasan yang tidak habis diminum, sehingga waktu penimbangan cairannya merembes kemana-mana, sehingga lengket dan bau.

Hasil wawancara dengan pengepul SampahQu, bahwa pihak pabrik tetap memotong 25\% UBC yang dikirimnya, walaupun sudah di-press atau dibal dan kondisi UBC jauh lebih bersih daripada pengepul dari TPA. Hal ini sama dengan tahun sebelumnya, dimana pengepul mengirim dalam keadaan di-press manual dan dimasukkan dalam karung dan masih berisi sedotan, maka dari checker mendapat potongan $25 \%$ dari harga belinya, dan 
Helena Juliana Kristina, Wilson Kosasih, Lithrone Laricha S.

hal ini merugikan pengepul. Hasil evaluasi menunjukkan bahwa perlu terus dibangun hubungan kerjasama, saling menghargai dan memahami antara semua mitra dalam kegiatan yang sudah berjalan. Hasil evaluasi juga menunjukkan opini dari pengurus bank sampah bahwa PT. Tetra Pak Indonesia sudah peduli pada permasalahan sampah kemasannya.

\section{UCAPAN TERIMA KASIH}

Penelitian ini didukung oleh PT. Tetra Pak Indonesia, dan mendapatkan dana hibah dari Lembaga Penelitian dan Pengabdian Masyarakat Universitas Tarumanagara. Pada kesempatan ini Penulis mengucapkan terima kasih kepada semua pihak yang mendukung, dan memberikan wawasan yang sangat membantu penelitian ini.

\section{DAFTAR PUSTAKA}

[1] Asroel, Hoesein. 2019. Bank Sampah: Masalah dan Solusi. Watampone, ID: Penerbit CV. Syahadah Creative Media.

[2] Kristina, H. J. 2014. Program Pemberdayaan Bank Sampah Masyarakat Berkelanjutan sebagai Salah Satu Penggerak Terwujudnya Reverse Logistic Manajemen Rantai Pasok Manufaktur Berkelanjutan. Paper presented at Seminar Nasional Teknologi dan Sains 2014. Jakarta, ID: Fakultas Teknik Universitas Tarumanagara.

[3] Geissdoerfer, M., Savaget, P., Bocken, N., \& Hultink, E. 2017. The Circular Economy - A New Sustainability Paradigm? Journal of Cleaner Production, 143(1), 757768. DOI: https://doi.org/10.1016/j.jclepro.2016.12.048

[4] Andreanto, Reza. 2018. Managing Sustainable Business. Paper presented at Seminar "Winning the Future, Today." Sheraton Hotel Gandaria City Jakarta, ID: GAPMMI dan Tetra Pak Indonesia.

[5] Kristina, H. J., Jobiliong, E., \& Christiani, A. 2018. Model Rantai Pasok Daur Ulang Kemasan Karton Yang Mengandung Aluminium Foil, Laporan Penelitian Prodi Teknik Industri Universitas Pelita Harapan, No: P-041-M/FaST/VIII/2018.

[6] Kristina, H. J., Kosasih, W., \& Salomon, L. L. 2019. Ergonomi Partisipasi dalam Mempromosikan Pengelolaan Sampah Mandiri dan Daur Ulang Kemasan Tetra Pak. Jurnal Bakti Masyarakat Indonesia, 2(2), 38-48.

DOI: https://doi.org/10.24912/jbmi.v2i2.7223

[7] Manuaba, Adnyana.1999. Penerapan Pendekatan Ergonomi Partisipasi Dalam Meningkatkan Kinerja Industri. Paper presented at Seminar Nasional Ergonomi Reevaluasi Penerapan Ergonomi dalam Meningkatkan Kinerja Industri. Surabaya, Indonesia.

[8] Vink, P., Imada, A. S. \& Zink, K. J. 2008. Defining Stakeholder Involvement in Participatory Design Processes. Journal of Applied Ergonomics, 39, 519-526.

[9] Dua, Mikhael. 2008. Filsafat Ekonomi: Upaya Mencari Kesejahteraan Bersama. Yogyakarta, ID: Pustaka Filsafat, Penerbit PT. Kanisius.

[10]Clayton, S. \& Myers, G. 2015. Conservation Psychology: Understanding and Promoting Human Care for Nature. UK: John Wiley \& Sons Ltd. 